\title{
Importance of vitamin D among patients with recurrent acute otitis externa
}

\author{
(1) Fuat Bulut ${ }^{1}$, (1) Kemal Kef², (1) Aylin Türksever ${ }^{3}$ \\ 1/stanbul Rumeli University, Corlu REYAP Hospital, Department of Otorhinolaryngology, Istanbul, Turkey \\ 2Private Kesan Hospital, Clinic of Otorhinolaryngology, Edirne, Turkey \\ 3Vocational College of Health Services of Rumeli University, Istanbul, Turkey
}

\section{Date submitted:}

15.07.2020

Date accepted:

31.08.2020

Online publication date:

15.03.2021

\section{Corresponding Author:}

Fuat Bulut MD, Istanbul Rumeli University, Corlu REYAP Hospital, Department of Otorhinolaryngology, Istanbul, Turkey

bulutfuat40@yahoo.com

ORCID:

orcid.org/0000-0003-3803-7987

Keywords: Vitamin D, otitis externa, ear canal, risk factors, infections

\begin{abstract}
Aims: The aim of this study is to analyze blood serum $25-\mathrm{OH}$ vitamin $\mathrm{D}$ levels among patients diagnosed with recurrent acute otitis externa $(\mathrm{OE})$.

Methods: This research was conducted among a total of 147 patients having applied to Private Corlu Reyap Hospital and Private Kesan Hospital Otorhinolaryngology Outpatient Clinic. 59 patients within the age range of $18-45$ years (mean age 32.3 years) with recurrent acute OE were selected. Patients whose one of the ears displayed recurrent $\mathrm{OE}$ at least three or more times in the last two years were included in the scope of this research for which two groups were formed. Patients were expected to have no vitamin D intake 30 days prior to diagnosis. Patients were examined to estimate serum blood levels of $25-\mathrm{OH}$ vitamin D.

Results: 88 patients with no recurrent acute OE were placed into the control group (1) whereas 59 patients with recurrent acute $\mathrm{OE}$ story were placed into group (2). $25-\mathrm{OH}$ vitamin $\mathrm{D}$ results of group (1) varied between 15 and $54 \mathrm{ng} / \mathrm{mL}$ and $25-\mathrm{OH}$ vitamin D results in group (2) moved in between 3 and $42 \mathrm{ng} / \mathrm{mL}$. In the control group (1), the mean ratio was 32.13, the mean standard error was 0.826 . In group (2), the mean ratio was 20.54 and the mean standard error was 0.896 . Compared to the control group, serum $25-\mathrm{OH}$ vitamin D levels in recurrent OE group were measured to be in a statistically low level $(p=0.000)$.
\end{abstract}

Conclusions: This study shows the relationship between vitamin D deficiency and recurrent acute $\mathrm{OE}$.

\section{Introduction}

Meatus acusticus externus is an anatomic formation with an approximate length of $2.5 \mathrm{~cm}$ and under normal circumstances, it manifests an ability to enable external epithelial migration with itself cleaning capacity. About one-third of external canal consists of cartilage formation, fat layer, apocrine glands and pilar formations. Thanks to its antimicrobial lysozyme characteristic, apocrine glands produce a cerumen layer offering protection. Cerumen has a 6.9 of $\mathrm{pH}$ level which can stop microbial growth (1). Otitis externa (OE) is defined as an inflammation measured at different degrees on the external surface of auricula, meatus acusticus externus or tympanic membrane (2). It was defined in 1844 by Mayer (3) at first. OE is a disease that affects daily life. Just in one year, it can affect every four people out of 1000. Diagnosis is made upon a physical examination that involves autoscopy concomitant with patient history. Clinical indications are characterized by irritation, pain and erythematous meatus acusticus externus. As the disease progresses, otorrhea and conductive hearing loss may develop (4). OE is categorized under four groups as; localized or pervasive, acute or chronic (5). Acute form of OE is primarily bacteria derived ( $90 \%$ of all cases). It can also develop due to fungi, viral and allergic dermatological disorders. In OE formation, some of inducing factors are water exposure on external ear, high temperature or high humidity in the environment, lowness or absence of cerumen, continuous stimulation with foreign objects in external auditory canal, hearing aids plugged into external auditory canal, ear plugs, psoriasis, dermatitis and radiation therapy (6).

Vitamin D plays a vital role in human body. In recent studies, the relationship between vitamin $\mathrm{D}$ deficiency and otologic 
Bulut et al. Importance of vitamin D among patients with recurrent acute otitis externa

disorders has been documented. Vitamin D deficiency has been associated with otitis media with effusion (7), retraction pocket formation and cholesteatoma (8), tympanostomy tubes (9), allergic dermatitis (10) and chronic otitis media (11). In many of the human tissues and human cells, vitamin $D$ as exists 1,25-dehydroxcolecalciferol $\left[1,25-(\mathrm{OH})_{2} \mathrm{D}_{3}\right]$ or cholecalciferol and its active form is recognized as vitamin $D_{3}(12)$. It manifests anti-inflammatory and immunomodulator function and displays vitamin $D$ and vitamin D binding protein (VDBP) (13). Vitamin $D$ creates its effect through vitamin D receptor (14). Vitamin D decreases the expression of matrix metalloproteinase (MMPs) (15) considered to be secreted by the skin colonizer bacteria in fibroblast (HFL-1) cells; therefore, vitamin D causes inhibition in MMP activity (16). Studies have shown that inflammatory skin disorders of vitamin $D$ are partially mediated by human neutrophile elastase (HNE) (17) and MMPs (18).

In this study, we aim to demonstrate the importance of 25$\mathrm{OH}$ vitamin $\mathrm{D}$ levels among patients with recurrent acute $\mathrm{OE}$. By means of this research, it will be feasible to prevent potential complications due to recurrent acute $\mathrm{OE}$ and diminish labor force losses as well as treatment costs. Best of our literature review has validated that there is not yet any research exhibiting the relationship between recurrent acute $\mathrm{OE}$ and $25-\mathrm{OH}$ vitamin $\mathrm{D}$ levels.

\section{Methods}

This research was conducted among a total of 147 patients having applied to Private Corlu Reyap Hospital and Private Kesan Hospital Otorhinolaryngology Outpatient Clinic between June 2019 and December 2019. Fifty-nine patients within the age range of $18-45$ years (mean age 32.3 years) with recurrent acute OE were selected. Recurrent acute OE diagnosis of our patients was based on patient history and physical examination that involved autoscopy. Patients whose one of the ears displayed recurrent $\mathrm{OE}$ at least three or more times in the last two years were included in the scope of this research for which two groups were formed as those having received recurrent OE diagnosis and those not having recurrent OE diagnosis. Fiftynine patients were diagnosed with recurrent acute OE and 88 control group patients were examined to estimate serum blood levels of $25-\mathrm{OH}$ vitamin D. Blood serum levels of the patients were tested in otorhinolaryngology outpatient clinic and OE diagnoses were recorded for all patient groups.

The control group consisted of patients having applied with complaints irrelevant to OE, whose serum $25-\mathrm{OH}$ vitamin D levels were measured, and the control group patients were selected from those who did not filed any hospital application due to OE two years before the visit.

Inclusion criteria: Those having received recurrent acute OE diagnosis based on patient history and examination.
Exclusion criteria: Having a systemic disease, having a chronic disease except recurrent acute OE disease, receiving vitamin $\mathrm{D}$ therapy within the last 30 days, neuromuscular and immunological disorders, craniofacial and defined genetic abnormalities. Patients below 18 and above 45 years were also excluded. Research protocol was approved by the Ethics Committee (protocol no: 2020.08.01.08, date: 04.02.2020) of Namik Kemal University Medical Faculty and written informed consents of the patients were also collected.

In every group, the mean age of the patients was as follows; control group (1): $31.58 \pm 5.688$ years; group (2): $32.95 \pm 7.160$ years.

\section{Blood Serum Collection and Biochemical Analyses}

Prior to the test measurement, 8-12 hours of hunger is required. Analyses of serum blood levels were performed and serum levels of 25-hydroxyvitamin $\mathrm{D}_{3}\left[25(\mathrm{OH}) \mathrm{D}_{3}\right]$ were included in the study. Blood samples were taken from venous blood. To quantify the $25-\mathrm{OH}$ vitamin $\mathrm{D}$ chemiluminescence microparticle immuno examination (CMIA) measurement system, an Alinity i (Abbott) device and 25-OH vitamin $\mathrm{D}$ reagent kit $08 \mathrm{P} 45$ were used. Blood samples, anti-vitamin D coated paramagnetic microparticular and diluents were mixed and incubated. Existing $25-\mathrm{OH}$ vitamin $\mathrm{D}$ in the sample was removed from the VDBP and bound to microparticules coated with anti-vitamin D. To form a reaction mixture, vitamin $\mathrm{D}$ acridinium marked conjugate was added. After one washing session, pre-trigger and trigger solutions were mixed in the solution. Lastly, the obtained chemiluminescence reaction was measured in relative light unit (RLU) form. There was a relationship between the $25-\mathrm{OH}$ vitamin D amount in the sample and RLU detected by the optical components of the system. In the serum, the targeted vitamin $\mathrm{D}$ range was a minimum of $30-40 \mathrm{ng} / \mathrm{mL}$.

\section{Statistical Analysis}

Statistical analysis was performed via SPSS 22 software program. Intergroup comparisons were conducted by employing independent t-test. Accuracy of the test was computed as 95\%. $\mathrm{P}<0.05$ was accepted as the statistically significant level.

\section{Results}

This research provides $25-\mathrm{OH}$ vitamin $\mathrm{D}$ levels of a total of 147 patients. 25-OH vitamin D results of group (1) varied between 15 and $54 \mathrm{ng} / \mathrm{mL}$ and 25-OH vitamin $\mathrm{D}$ results in group (2) moved in between 3 and $42 \mathrm{ng} / \mathrm{mL}$. In the control group (1), the mean ratio was 32.13 , the mean standard error was 0.826 . In group (2), the mean ratio was 20.54 and the mean standard error was 0.896 . In this study, the mean age of the control group (1) patients was $31.58 \pm 5.688$ years. The mean age of patients with recurrent acute $\mathrm{OE}$ in group (2) was $32.95 \pm 7.160$ years. Compared to the control group, serum 25-OH vitamin D levels in recurrent $\mathrm{OE}$ group were measured to be in a statistically 
low level $(p=0.000)$. Research groups were designed as below (Table 1, Figure 1).

\begin{tabular}{|c|c|c|c|}
\hline & $\begin{array}{l}\text { Control group (1) } \\
(n=88)\end{array}$ & $\begin{array}{l}\text { Group (2) } \\
(n=59)\end{array}$ & $\mathrm{p}^{*}$ \\
\hline $\begin{array}{l}25-\mathrm{OH} \text { vitamin D } \\
\text { (mean } \pm \text { standard } \\
\text { error mean) }\end{array}$ & $32.13 \pm 0.826$ & $20.54 \pm 0.896$ & 0.000 \\
\hline \multicolumn{4}{|c|}{$\begin{array}{l}\text { Control group (1): Patients with no recurrent acute OE, group (2): Patients with } \\
\text { recurrent acute OE. } \\
\text { Control group (1) }(n=88) \text { and group (2) }(n=59),{ }^{*} p<0.0001 . \\
\text { OE: Otitis externa }\end{array}$} \\
\hline
\end{tabular}

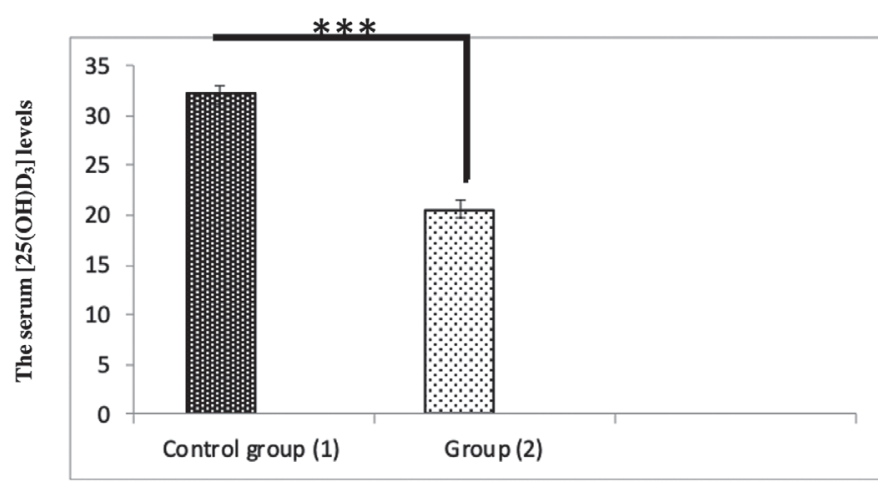

Figure 1. The serum $\left[25(\mathrm{OH}) \mathrm{D}_{3}\right]$ levels of patients. Comparison of serum $\left[25(\mathrm{OH}) \mathrm{D}_{3}\right.$ ] levels control group (1) $(n=88)$ and group $(2)(n=59)$ ${ }^{* * *} p<0.0001$

\section{Discussion}

A review of relevant literature shows that there is not yet any research having examined $25-\mathrm{OH}$ vitamin $\mathrm{D}$ levels among patients with recurrent acute OE. In our research, we detected that blood serum 25-OH vitamin D levels of patients with recurrent acute OE were in statistically significantly low level.

$25-\mathrm{OH}$ vitamin $\mathrm{D}$ is the best indicator of vitamin $\mathrm{D}$ level in our body. Today, 25-OH vitamin $\mathrm{D}$ level below $20 \mathrm{ng} / \mathrm{mL}$ in human blood is accepted as deficiency, $20-30 \mathrm{ng} / \mathrm{mL}$ level is accepted as inadequacy and $\geq 30 \mathrm{ng} / \mathrm{mL}$ level as adequate. Thresholds and significance of these values are based on a myriad of studies and a range of reference guidelines (19). Among our patients who had recurrent acute $O E$, vitamin $D$ results were measured as $20.54 \mathrm{ng} / \mathrm{mL}$. In another research, it was reported that 50 percent of the children with otitis media with effusion displayed vitamin D levels below $50 \mathrm{nmol} / \mathrm{L}$ (9).

Recurrent acute OE diagnosis of our patients was made based on patient history and a physical examination that entailed autoscopy. Patients whose one of the ears displayed recurrent $O E$ at least three or more times in the last two years were included in the scope of this research. Chronic OE is a clinical manifestation lasting longer than four weeks or displaying four or more attacks in one year term (20). As for our patients, clinical manifestation of OE continued shorter than four weeks. In our research, clinical indications among the patients were characterized by pain, irritation and erythematous external canal. Thirteen of all cases (22\%) manifested seropurulent discharge and conductive hearing loss. Among 45 (76.2\%) recurrent acute $\mathrm{OE}$ cases, we detected very intense ear pain. Among five patients $(8 \%)$, there was pain in jaw joint part in tandem with difficulty in chewing. In our cases, 40 patients $(67.7 \%)$ maintained cerumen insufficiency. A conducted research proved the protective role of cerumen in recurrent OE (21). Despite genetic disposition, agerelated factors that call for individual metabolism are equally effective in cerumen manifestation. In our cases, there was not any family history and 15 cases $(25.4 \%)$ shared their swimmingrelated history in our research.

The mean age of our patients was computed as $32.95 \pm 7.160$ years. Although OE can be monitored in every age group, it is mostly detected above the age of two years, mainly observed between the ages of 5 and 14 years (22). In acute OE progress, the history of using a hearing aid is vital since its usage increases a predisposition for OE formation. None of our patients had a background in using a hearing aid. OE is more common in regions with a hot and humid climate, while our research was taken place in cool regions. Despite the presence of regional variations, a vast majority of $\mathrm{OE}$ cases emerge during summer season and between June and August. Our cases were evaluated between the months June and December.

In recurrent chronic otorhinolaryngology disorders, bacterial biofilms were found to be related to acute otitis media, chronic tonsillitis and chronic rhinosinusitis (23-25). Human cathelicidin linked with vitamin $\mathrm{D}$ is a peptide termed as LL-37 and displays a bactericide activity. In vitro studies showed that breakdown product of human cathelicidin's free C-terminal LL-37 could stop the formation of Pseudomonas aeruginosa biofilms (26). Our previous research also displayed the effect of n-acetylcysteine and acetylsalicylic acid on bacterial biofilm (27).

In an international research, it was reported that among adults in New Zealand, serum vitamin D concentrations were typically at maximum level in March and minimum level in August (28). In our research, blood sampling was performed during June and December when vitamin $D$ levels were expected to be in the midrange.

Conducted studies have revealed that vitamin D plays a critical mediator role in the production of antimicrobial peptides (cathelicidins and defensins) (29). It was also reported that vitamin D significantly elevates the production of cathelicidin, which has a direct antimicrobial function in keratinocytes (30). In another research, findings have proved that high MMP levels in ear canal and interrelation with HNE levels could play a role in the chronic OE pathogenesis (31). We hold the belief 
that vitamin $D$ deficiency played a role through the means of cathelicidin, MMP and HNE in recurrent acute OE.

For treatment, we applied extensive local hygiene, topical antibiotics, systemic antimicrobial therapy and anti-inflammatory agent to our patients. Besides, in the treatment of OEs chronic form, debridement, acidification and topical corticosteroid applications are well reported in the literature (32).

Chronic OE has been associated with low life quality (33). Its negative influence on the life quality was also declared by our patients. It is suggested to conduct a differential diagnosis between $\mathrm{OE}$ and middle ear disorder, malignant $\mathrm{OE}$ and choleasteatoma (34). Results of our research suggests that $25-\mathrm{OH}$ vitamin $\mathrm{D}$ deficiency is an age and gender independent factor that can promote the growth of recurrent acute OE.

It should be noted that there are certain factors limiting this research. First, we conducted this study with a limited number of patients. Second limitation is not having measured MMPs and VEGF levels.

\section{Conclusion}

In this research, we attempted to manifest vitamin $D$ levels among patients with recurrent acute OE and we demonstrated clinical significance of vitamin D. In recurrent acute $O E$, the cause of resistance against medical treatment could be related to low vitamin D levels. Future prospective studies on vitamin D could better illustrate the importance of these vitamins in the resistance against medical treatment in case of otorhinolaryngologic disorders and emergence of recurrent attacks. Having some awareness on the relationship of vitamin $D$ with recurrent acute OE would play a salient role in preventing complications of disorders, lowering labor force losses and treatment costs. For the patients with recurrent acute $\mathrm{OE}$ and vitamin $\mathrm{D}$ deficiency, vitamin D supplementation could ameliorate characteristic clinical indications of the disease. In the future, researches with larger quantities of patients could provide further contributions to the topic.

\section{Ethics}

Ethics Committee Approval: Research protocol was approved by the Ethics Committee (protocol no: 2020.08.01.08, date: 04.02.2020) of Namık Kemal University Medical Faculty.

Informed Consent: Written informed consent of the patients was collected.

Peer-review: Externally peer-reviewed.

\section{Authorship Contributions}

Concept: F.B., Design: K.K., Data Collection or Processing: F.B., K.K., Analysis or Interpretation: F.B., Literature Search: F.B., Writing: A.T.
Conflict of Interest: No conflict of interest was declared by the authors.

Financial Disclosure: The authors declared that this study received no financial support.

\section{References}

1. Rowlands S, Devalia H, Smith C, Hubbard R, Dean A. Otitis externa in UK general practice: a survey using the UK General Practice Research Database. Br J Gen Pract. 2001;51:533-538.

2. Wang X, Winterstein AG, Li Y, Zhu Y, Antonelli PJ. Use of Systemic Antibiotics for Acute Otitis Externa: Impact of a Clinical Practice Guideline. Otol Neurotol. 2018;39:10881094.

3. Pattison I. Thomas Mayer, Thomas Walton Mayer and the veterinary surgeons charter of 1844 . Vet Hist. 19831984;3:43-49.

4. Osguthorpe JD, Nielsen DR. Otitis externa: Review and clinical update. Am Fam Physician. 2006;74:1510-1516.

5. Schapowal A. Otitis externa: a clinical overview. Ear Nose Throat J. 2002;81(8 Suppl 1):21-22.

6. Beers SL, Abramo TJ. Otitis externa review. Pediatr Emerg Care. 2004;20:250-256.

7. Bartley J. Vitamin D, innate immunity and upper respiratory tract infection. J Laryngol Otol. 2010;124:465-469.

8. Taneja MK, Taneja V. Role of vitamin D in prevention of deafness. Indian Journal of Otology. 2012;18:55-57.

9. Linday LA, Shindledecker RD, Dolitsky JN, Chen TC, Holick MF. Plasma 25-hydroxyvitamin D levels in young children undergoing placement of tympanostomy tubes. Ann Otol Rhinol Laryngol. 2008;117:740-744.

10. Borzutzky A, Camargo CA Jr. Role of vitamin D in the pathogenesis and treatment of atopic dermatitis. Expert Rev Clin Immunol. 2013;9:751-760.

11. Walker RE, Bartley J, Camargo CA Jr, Flint D, Thompson JMD, Mitchell EA. Higher serum 25(OH)D concentration is associated with lower risk of chronic otitis media with effusion: a case-control study. Acta Paediatr. 2017;106:1487-1492.

12. Ross AC, Taylor CL, Yaktine AL, Del Valle HB. Dietary Reference Intakes for Calcium and Vitamin D. Washington (DC): National Academies Press (US); 2011.

13. Chishimba L, Thickett DR, Stockley RA, Wood AM. The vitamin $D$ axis in the lung: a key role for vitamin D-binding protein. Thorax. 2010;65:456-462.

14. Gombart AF, Borregaard N, Koeffler HP. Human cathelicidin antimicrobial peptide (CAMP) gene is a direct target of the vitamin $D$ receptor and is strongly up-regulated in myeloid cells by 1,25-dihydroxyvitamin D3. FASEB J. 2005; 19:10671077.

15. Miedzobrodzki J, Kaszycki P, Bialecka A, Kasprowicz A. Proteolytic activity of Staphylococcus aureus strains 
isolated from the colonized skin of patients with acutephase atopic dermatitis. Eur J Clin Microbiol Infect Dis. 2002;21:269-276.

16. Whyte J, Sarrat R, Diaz P, et al. [Effects of experimental vasectomy on testicular structure: ultrastructural study]. Actas Urol Esp. 1999;23:309-315.

17. Rogalski C, Meyer-Hoffert U, Proksch E, Wiedow O. Human leukocyte elastase induces keratinocyte proliferation in vitro and in vivo. J Invest Dermatol. 2002;118:49-54.

18. Katoh N, Hirano S, Suehiro M, Ikenaga K, Yasuno $\mathrm{H}$. Increased levels of serum tissue inhibitor of metalloproteinase-1 but not metalloproteinase-3 in atopic dermatitis. Clin Exp Immunol. 2002;127:283-288.

19. Manson JE, Brannon PM, Rosen CJ, Taylor CL. Vitamin D Deficiency - Is There Really a Pandemic? N Engl J Med. 2016;375:1817-1820.

20. Martinez Devesa P, Willis CM, Capper JW. External auditory canal $\mathrm{pH}$ in chronic otitis externa. Clin Otolaryngol Allied Sci. 2003;28:320-324.

21. Pata YS, Ozturk C, Akbas Y, Gorur K, Unal M, Ozcan C. Has cerumen a protective role in recurrent external otitis? Am J Otolaryngol. 2003;24:209-212.

22. McWilliams CJ, Smith $\mathrm{CH}$, Goldman RD. Acute otitis externa in children. Can Fam Physician. 2012;58:12221224.

23. Palmer J. Bacterial biofilms in chronic rhinosinusitis. Ann Otol Rhinol Laryngol Suppl. 2006;196:35-39.

24. Macassey E, Dawes P. Biofilms and their role in otorhinolaryngological disease. $\mathrm{J}$ Laryngol Otol. 2008;122:1273-1278.
25. Hunsaker DH, Leid JG. The relationship of biofilms to chronic rhinosinusitis. Curr Opin Ootolaryngol Head Neck Surg. 2008;16:237-241.

26. Overhage J, Campisano A, Bains M, Torfs ECW, Rehm BHA, Hancock REW. Human host defense peptide LL37 prevents bacterial biofilm formation. Infect Immun. 2008;76:4176-4182.

27. Bulut F, Meric F, Yorgancilar E, et al. Effects of N-acetylcysteine and acetylsalicylic acid on the tonsil bacterial biofilm tissues by light and electron microscopy. Eur Rev Med Pharmacol Sci. 2014;18:3720-3725.

28. Lucas JA, Bolland MJ, Grey AB, et al. Determinants of vitamin $D$ status in older women living in a subtropical climate. Osteoporos Int. 2005;16:1641-1648.

29. Watkins RR, Yamshchikov AV, Lemonovich TL, Salata RA. The role of vitamin $D$ deficiency in sepsis and potential therapeutic implications. J Infect. 2011;63:321-326.

30. Wang TT, Nestel FP, Bourdeau V, et al. Cutting edge: 1,25-dihydroxyvitamin D3 is a direct inducer of antimicrobial peptide gene expression. J Immunol. 2004;173:2909-2912.

31. Antonelli PJ, Schultz GS, Cantwell JS, Sundin DJ, Pemberton PA, Barr PJ. Inflammatory proteases in chronic otitis externa. Laryngoscope. 2005;115:651-654.

32. Roland PS. Chronic external otitis. Ear Nose Throat J. 2001;80(6 Suppl):12-16.

33. Ali R, Burns P, Donnelly M. Otitis externa: quality of life assessment. Irish J Med Sci. 2008;177:221-223.

34. Levy SB. The Antibiotic Paradox: How the Misuse of Antibiotic Destroys Their Curative Powers. Cambridge, MA: Perseus Publishing; 2002. 